\title{
Electrical, Structural and Morphological Properties of Sb-Doped Bi-Based Superconductors
}

\author{
Ghazala Y. Hermiz, Amal K. Jassim, Saad F. Oboudi \\ Department of Physics, College of Science, University of Baghdad, Baghdad, Iraq \\ Email: gyhermiz@yahoo.com
}

Received 14 May 2015; accepted 22 June 2015; published 26 June 2015

Copyright @ 2015 by authors and Scientific Research Publishing Inc.

This work is licensed under the Creative Commons Attribution International License (CC BY).

http://creativecommons.org/licenses/by/4.0/

(c) (i) Open Access

\section{Abstract}

In this paper, samples of antimony doped Bi-based superconductor with stoichiometric composition $\mathrm{Bi}_{1.7} \mathrm{~Pb}_{0.2} \mathrm{Sb}_{0.1} \mathrm{Sr}_{2} \mathrm{Ca}_{2} \mathrm{Ca}_{3} \mathrm{O}_{10}$ were prepared by a solid state reaction method. The effect of sintering time on the superconducting properties was studied; all samples were sintered in air at $850^{\circ} \mathrm{C}$ for different sintering time $(80,100,120,140$, and 160$) \mathrm{h}$. X-ray diffraction (XRD) and scanning electron microscopy (SEM) measurements were performed for determination of the crystal structure and surface morphology of samples, respectively. All samples showed an orthorhombic structure with two phases, high-Tc phase $(2223)$ and low- $T_{c}$ phase $(2212)$ in addition to an impure phase. It has been observed that the critical temperature and the high- $T_{c}$ phase increases and appears to be the dominant phase when the sintering time is increased to $140 \mathrm{~h}$, while with increasing sintering time to $160 \mathrm{~h}$, both $\mathrm{T}_{\mathrm{c}}$ and the high phase started to decrease. (SEM) results show that increasing sintering time enhances the growing of superconducting phase unidirectional and suppresses the high phase intrusion which leads to the production of nearly single Bi-2223 phase with higher $\mathbf{T}_{\mathrm{c}}$.

\section{Keywords}

(Bi, Pb) Superconductors, Sb Substitution, Sintering Time

\section{Introduction}

Among high- $\mathrm{T}_{\mathrm{c}}$ superconductors, Bi-2223 compound with the superconducting critical temperature $\mathrm{T}_{\mathrm{c}} \approx 110 \mathrm{~K}$ is one of the promising candidates for practical applications, such as power transmission cables, flexible wire or tape carrying high density of current at liquid nitrogen temperature [1] [2]. It is now well known that the Bi- 
based system has layered structure and according to their compositions, it has three different phases: Bi-(2201), Bi-(2212), and Bi-(2223) [3] [4]. The Bi-2223 phase seems to dominate in all the three systems in spite of the fact that single-phase formation is very difficult. However, it has been reported that $\mathrm{Pb}$ doping at Bi-sites promotes the formation of single $\mathrm{Bi}-2223$ phase and leads to higher $\mathrm{T}_{\mathrm{c}}$ values by inducing a partially melted liquid phase, which eases the diffusion of elements that improve the connectivity between regions of the 2223 structure, and promotes the formation of a $\mathrm{Bi}-2223$ nearly single-phase sample. On the other hand, it increases their critical current density [5] [6].

The superconducting properties of $\mathrm{BiSrCaCuO}$ compounds can be controlled by the addition or substitution of impurity atoms with different ionic radius and different bonding characters that produces atomic level crystal defects, lattice strains, non-superconducting inclusions and other structural defects. These inhomogeneties can improve $T_{c}$. For successful results different receipts can be found in the literature [7]-[10]. Partial replacement of Bi by $\mathrm{Pb}(\mathrm{x} \leq 0.3)$ and $\mathrm{Sb}(\mathrm{y} \leq 0.2)$ doping produces materials of high $\mathrm{T}_{\mathrm{c}}$ phase purity [11], with Antimony playing an important role in accelerating the formation of the phase with higher superconductive transition in the Bi-system.

The role of Antimony appeared to be the enhancement of low- $\mathrm{T}_{\mathrm{C}}$ to high $\mathrm{T}_{\mathrm{c}}$ phase reaction beyond that achievable by lead incorporation alone [12]. The enhancement of $\mathrm{T}_{\mathrm{c}}(0)$ by Sb-content in $\mathrm{Bi}_{1.7} \mathrm{Tl}_{0.3-\mathrm{x}} \mathrm{Sb}_{\mathrm{x}} \mathrm{Pb}_{0.4} \mathrm{Sr}_{2} \mathrm{Ca}_{2} \mathrm{Cu}_{3} \mathrm{O}_{\mathrm{y}}$ system is also reported by Iqbal et al. [13]. The presence of antimony, as $\mathrm{Sb}_{2} \mathrm{O}_{3}$, is believed to make the system more reactive, enhances the kinetics of the reaction and hence promotes the high- $\mathrm{T}_{\mathrm{c}}$ phase [14]. Antimony addition has been stated to be effective in preventing $\mathrm{Pb}$ from evaporating during calcinations, and produces stabilization in the formation of $\mathrm{Bi}-2223$ phase [12] [15] [16]. This work is aimed to investigate the sintering time effect on the superconducting properties of $\mathrm{Bi}_{1.7} \mathrm{~Pb}_{0.2} \mathrm{Sb}_{0.1} \mathrm{Sr}_{2} \mathrm{Ca}_{2} \mathrm{Ca}_{3} \mathrm{O}_{10}$ compound.

\section{Materials and Methods}

$\mathrm{Bi}_{1.7} \mathrm{~Pb}_{0.2} \mathrm{Sb}_{0.1} \mathrm{Sr}_{2} \mathrm{Ca}_{2} \mathrm{Ca}_{3} \mathrm{O}_{10}$ samples were prepared by a standard solid state reaction method. The stoichiometric amounts of high purity powders (99.999\%) of $\mathrm{Bi}_{2} \mathrm{O}_{3}, \mathrm{~Pb}_{3} \mathrm{O}_{4}, \mathrm{Sb}_{2} \mathrm{O}_{3}, \mathrm{Sr}\left(\mathrm{NO}_{3}\right)_{2}, \mathrm{CaO}$, and $\mathrm{CuO}$ were used as starting materials. The powders of precursor were mixed together by using agate mortar. The mixture homogenization takes place by adding a sufficient quantity of 2-propanol to form a paste during the process of grinding for about $1 \mathrm{~h}$. The mixture was grounded to a fine powder and then calcined in air by using a tube furnace at $800^{\circ} \mathrm{C}$ for $30 \mathrm{~h}$ with a rate of $2^{\circ} \mathrm{C} / \mathrm{min}$. The mixture then pressed into pellets by using hydraulic press type (SPECAC) under pressure of $0.7 \mathrm{GPa}$. Five sets of samples were sintered at $850^{\circ} \mathrm{C}$ for $80,100,120,140$, and $160 \mathrm{~h}$ in order to study the effect of sintering time on the superconducting properties of the prepared samples. In this work all samples were subjected to gross structural characterization by X-ray diffraction (XRD) (Philips, with CuKalpha source). A computer program was used to calculate the lattice parameters, based on Cohen's least square method. Resistance-temperature data were obtained by using four point probe DC method at temperature range (77 - 300) $\mathrm{K}$ to determine the critical temperature $\left(T_{c}\right)$. Scanning electron microscopy (SEM) was performed by (JEOL JSEM-5910).

\section{Results and Discussion}

The X-ray diffraction analysis was performed for all samples as shown in Figure 1. The results of $\mathrm{Bi}_{1.7} \mathrm{~Pb}_{0.2^{-}}$ $\mathrm{Sb}_{0.1} \mathrm{Sr}_{2} \mathrm{Ca}_{2} \mathrm{Ca}_{3} \mathrm{O}_{10}$ samples sintered for different periods of time (80, 100, 120, 140, and 160) $\mathrm{h}$ indicate that all samples have an orthorhombic structure with two phases; high- $\mathrm{T}_{\mathrm{c}}$ phase (2223) and low- $\mathrm{T}_{\mathrm{c}}$ phase (2212), in addition to a small amount of impurity phases of $\mathrm{Sr}_{2} \mathrm{Ca}_{2} \mathrm{Cu}_{7} \mathrm{O}$ in all samples at $2 \theta=36.8^{\circ}$ [17]. The occurrence of all those non-superconducting impurity phases will lead to a reduction of the $\mathrm{T}_{\mathrm{c}}$ for all samples. The appearance of more than two phases could be related to the stacking faults along the c-axis. The intensity and peak position of reflections are in good agreement with the values reported in the literature. Also, it is clear that the relative intensity and peak positions vary slightly with increasing sintering time, which causes a change in the lattice constant of the sample. This result indicates that all samples were mainly consisting of (2212) and (2223) phases. Although the impurity phase of $\mathrm{Sr}_{2} \mathrm{Ca}_{2} \mathrm{Cu}_{7} \mathrm{O}$ peak at $2 \theta=36.8^{\circ}$ looks slightly higher in the samples sintered for $140 \mathrm{~h}$, the (2223) phase being the dominant one as shown in Table 1 . The peaks belonging to the (2223) phase were indexed with respect to an orthorhombic unit cell. Also, similar results were obtained by Saleh [18]. Increasing sintering time may well enhance crystallinity and the peaks to be sharper. The most intense peak pattern of samples belongs to the high- $\mathrm{T}_{\mathrm{c}}$ phase, which also indicates an increase in the volume fraction of the 2223 


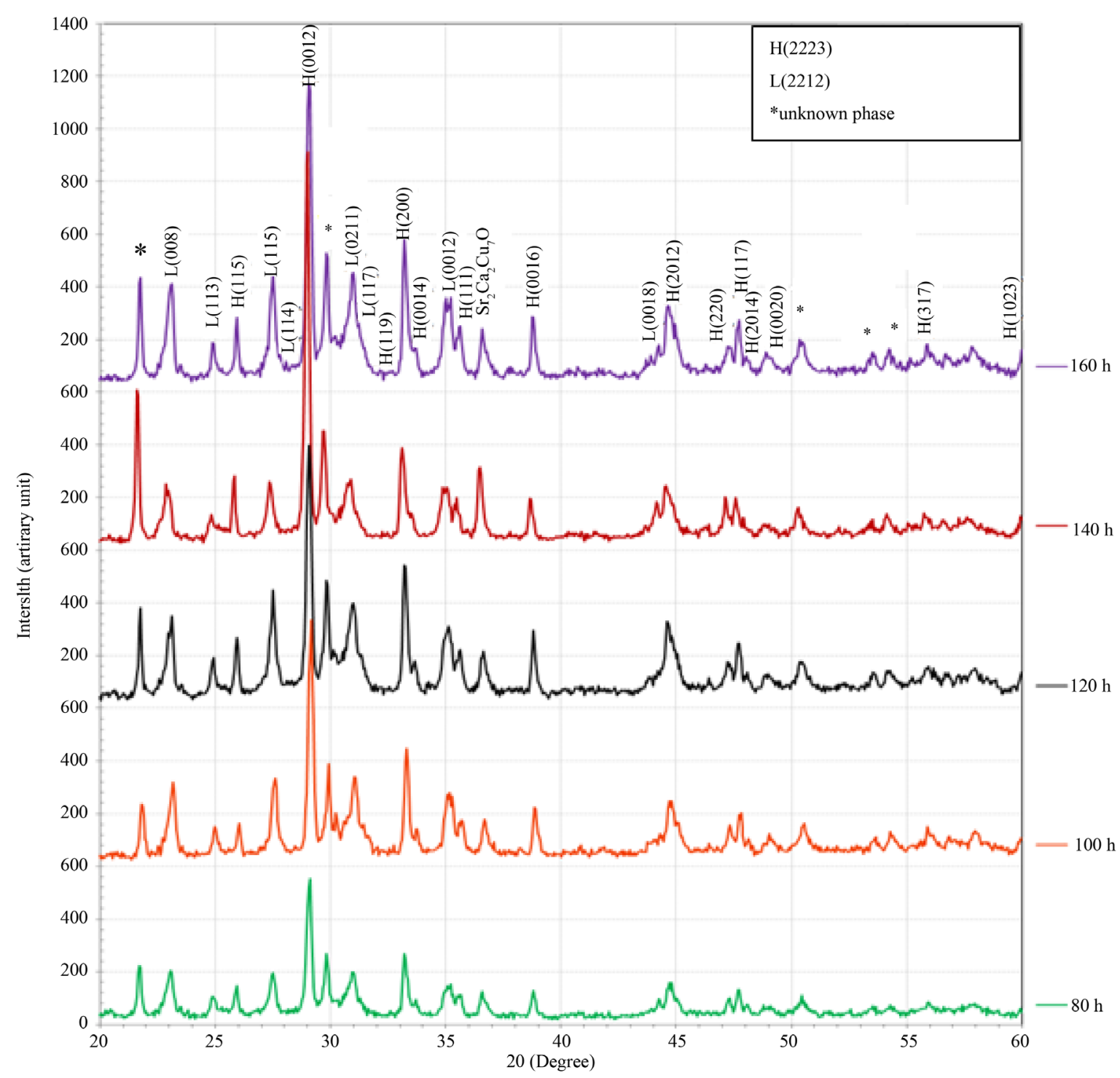

Figure 1. XRD patterns of $\mathrm{Bi}_{1.7} \mathrm{~Pb}_{0.2} \mathrm{Sb}_{0.1} \mathrm{Sr}_{2} \mathrm{Ca}_{2} \mathrm{Ca}_{3} \mathrm{O}_{10}$ sintered for $(80,100,120,140$ and 160) h.

Table 1. Lattice parameter, volume of the unit cell, critical temperature and percentage volume fraction of $\mathrm{Bi}$-(2223) and $\mathrm{Bi}$ (2212) phases in $\mathrm{Bi}_{1.7} \mathrm{~Pb}_{0.2} \mathrm{Sb}_{0.1} \mathrm{Sr}_{2} \mathrm{Ca}_{2} \mathrm{Ca}_{3} \mathrm{O}_{10}$ samples at different sintering time.

\begin{tabular}{ccccccccc}
\hline $\mathrm{t}_{\mathrm{s}}(\mathrm{h})$ & $\mathrm{a}(\AA)$ & $\mathrm{b}(\AA)$ & $\mathrm{c}(\AA)$ & $\mathrm{V}(\AA)^{3}$ & $\mathrm{c} / \mathrm{a}$ & $\mathrm{T}_{\mathrm{c}}$ & \multicolumn{2}{c}{ Volume fraction of phases formed (\%) } \\
\hline 80 & 5.391 & 5.418 & 37.081 & 1.083 & 6.878 & $<77$ & 56.1 & Bi-2212 phase \\
100 & 5.389 & 5.394 & 37.120 & 1.079 & 6.888 & $<77$ & 56.7 & 43.9 \\
120 & 5.388 & 5.387 & 37.139 & 1.078 & 6.892 & 84 & 62.1 & 37.9 \\
140 & 5.387 & 5.417 & 37.148 & 1.084 & 6.895 & 110 & 82.6 & 17.4 \\
160 & 5.390 & 5.397 & 37.091 & 1.078 & 6.881 & $<77$ & 64.2 & 35.8 \\
\hline
\end{tabular}

phase, and this leads to an increase in the $T_{c}$ value. Such result was also obtained by Kocabas [19].

We have used all the peaks of $\mathrm{Bi}-(2223)$ and $\mathrm{Bi}-(2212)$ phases for the estimation of the volume fraction of the phases using the following formulas [20]: 


$$
\begin{aligned}
\mathrm{Bi}-(2223) \% & =\frac{\sum \mathrm{I}(2223)}{\sum \mathrm{I}(2223)+\sum \mathrm{I}(2212)+\sum \mathrm{I}_{\text {other }}} \times 100 \\
\mathrm{Bi}-(2212) \% & =\frac{\sum \mathrm{I}(2212)}{\sum \mathrm{I}(2223)+\sum \mathrm{I}(2212)+\sum \mathrm{I}_{\text {other }}} \times 100
\end{aligned}
$$

where: I (2223), I (2212) and $\mathrm{I}_{\text {other }}$ are the intensities of Bi-2223 and Bi-2212 and other phases respectively. The volume fractions of the phases and lattice parameters a, b, c and c/a for all samples are given in Table 1 . This Table indicates that an increase of the sintering time from 120 to $140 \mathrm{~h}$. change the structural parameters. The deformation in the c-axis adjusts the amount of charge transfer from $\mathrm{Bi}-\mathrm{O}$ layer to $\mathrm{Cu}-\mathrm{O}$ layer sheet will tend to improve the critical temperature $\mathrm{T}_{\mathrm{c}}$. Increasing sintering time resulted in an increase in the volume fraction of Bi-2223 phase to $82.6 \%$ for the sample sintered for $140 \mathrm{~h}$. Also, a decrease in the peaks intensities of the 2212 phase was obtained. On the other hand, a decrease in the volume fraction of the high phase and the critical temperature $T_{c}$ was obtained with increasing sintering time to $160 \mathrm{~h}$.

The percent volume fraction of the 2223 and 2212 phases as a function of sintering temperature were calculated from the XRD patterns of the $\mathrm{Bi}_{1.7} \mathrm{~Pb}_{0.2} \mathrm{Sb}_{0.1} \mathrm{Sr}_{2} \mathrm{Ca}_{2} \mathrm{Ca}_{3} \mathrm{O}_{10}$ samples and are shown in Figure 2.

The electrical resistivity versus temperature plots at different sintering time is shown in Figure 3 . All samples show that the resistivity decreases linearly with temperature in the normal state. Furthermore, all samples displayed a metallic character above onset temperature. It can be observed from the plots that prolonged sintering time up to a certain maximum time could improve the critical temperature $\left(T_{c}\right)$ of stoichiometry composition. It is clear that the transition temperature increases from $84 \mathrm{~K}$ to $110 \mathrm{~K}$ with the increase of the sintering time from

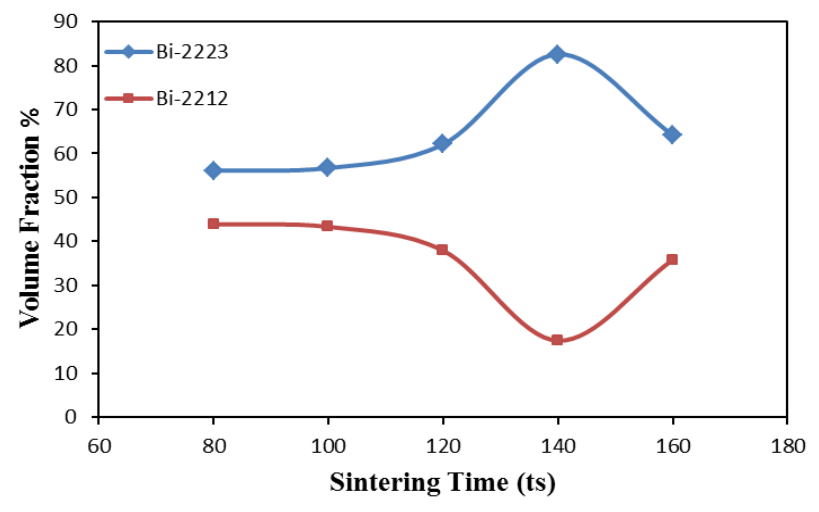

Figure 2. The volume fraction of $\mathrm{Bi}-(2223)$ and $\mathrm{Bi}-(2212)$ phases in $\mathrm{Bi}_{1.7} \mathrm{~Pb}_{0.2} \mathrm{Sb}_{0.1} \mathrm{Sr}_{2} \mathrm{Ca}_{2} \mathrm{Ca}_{3} \mathrm{O}_{10}$ samples at different sintering time.

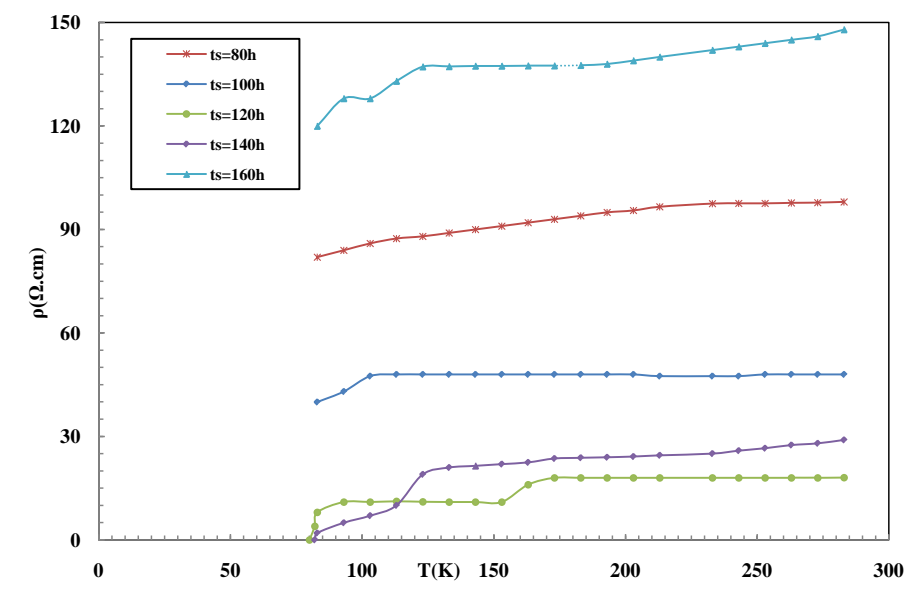

Figure 3. Temperature dependence of resistivity for $\mathrm{Bi}_{1.7} \mathrm{~Pb}_{0.2} \mathrm{Sb}_{0.1} \mathrm{Sr}_{2} \mathrm{Ca}_{2} \mathrm{Ca}_{3} \mathrm{O}_{10}$ sintered for $(80,100,120,140$ and 160) h. 
120 to $140 \mathrm{~h}$, which is related to the increasing of (2223) phase volume fraction. The increase in the $\mathrm{T}_{\mathrm{c}}$ value is mainly due to the strong link and increasing of the contact areas between grains, which have higher alignment along the c-axis as inferred from both XRD and SEM analyses. Such result was also obtained by Mizauno et al. [21]. They suggested that long sintering time will give a chance to insert extra layers of $\mathrm{Cu}-\mathrm{O}_{2}$ and $\mathrm{Ca}$ planes into the perovskite layers of the low- $\mathrm{T}_{\mathrm{c}}$ phase. Furthermore, it seems that the $\mathrm{Sb}$ is replaced in the $\mathrm{Pb}$ site in the sample structure, and the role of $\mathrm{Pb}$ is very important in the stability and in the enhanced percentage of $\mathrm{Bi}-2223$ phase. This result is confirmed by Shoushtari et al. [22]. On the other hand, when the samples sintered for $160 \mathrm{~h}$ the resistivity decreases slowly (as it behaves like a superconductor) but does not become zero, even at the boiling point of liquid nitrogen. The reduction of the critical temperature can be due to either the crack formation as a result of excessive mechanical deformation or due to amorphous phase formation during the sintering process.

The surface morphology for the prepared samples is shown in Figures 4(a)-(e). The grains of all samples are randomly plate-like grains and their size is found to increase with increasing sintering time. The occurrence of

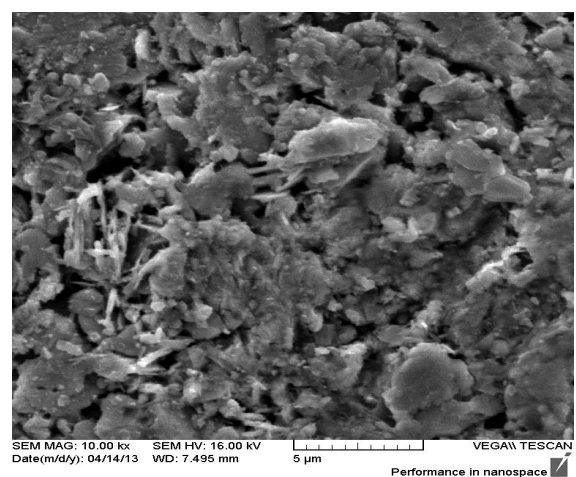

(a)

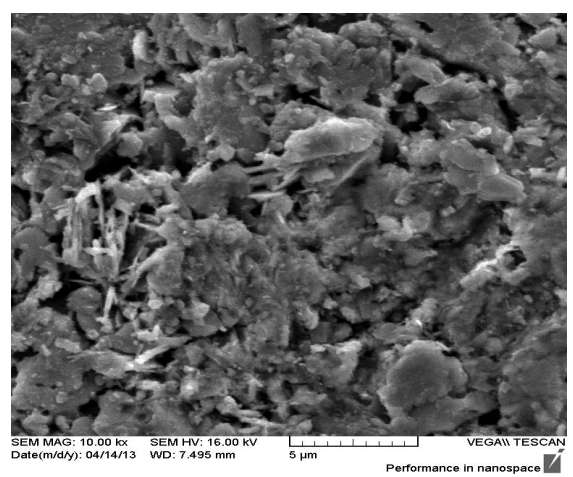

(b)

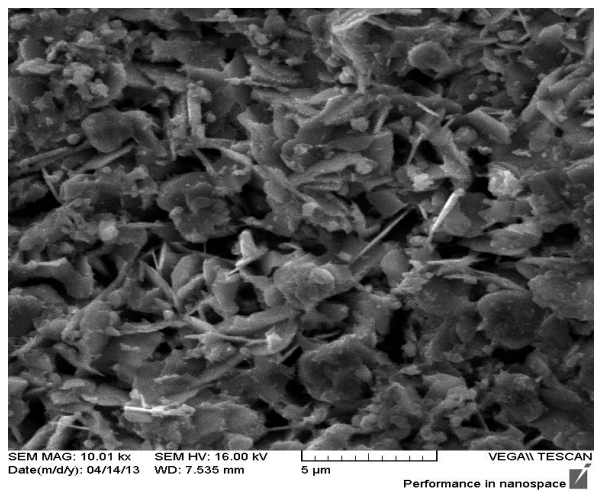

(d)

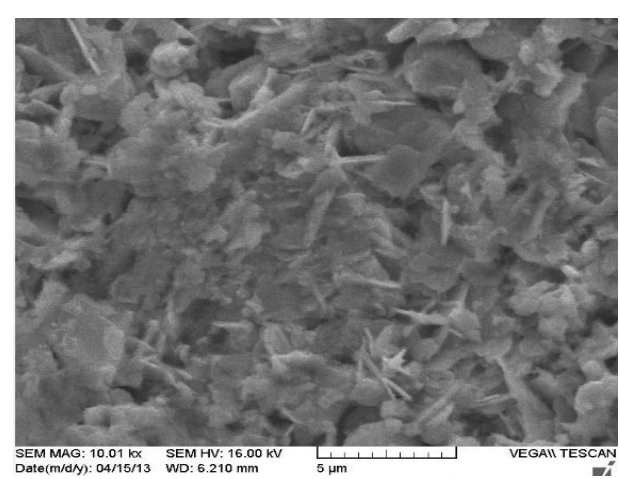

(c)

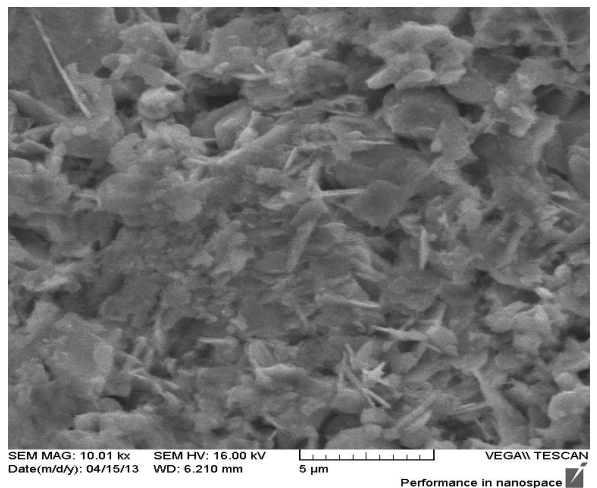

(e)

Figure 4. $\mathrm{SEM}$ images for $\mathrm{Bi}_{1.7} \mathrm{~Pb}_{0.2} \mathrm{Sb}_{0.1} \mathrm{Sr}_{2} \mathrm{Ca}_{2} \mathrm{Ca}_{3} \mathrm{O}_{10}$ samples with different sintering time: (a) $80 \mathrm{~h}$; (b) $100 \mathrm{~h}$; (c) $120 \mathrm{~h}$; (d) $140 \mathrm{~h}$; (e) $160 \mathrm{~h}$. 
grains with plate-like structure is a signature of the Bi-2223 phase formation from the Bi-2212 matrix mostly due to the prolonged sintering process [23]. Samples sintered for 80 and $100 \mathrm{~h}$ show a small amount of spherelike grains, which could be due to the $\mathrm{Sr}_{2} \mathrm{Ca}_{2} \mathrm{Cu}_{7} \mathrm{O}$ solid particles that are randomly distributed over the phase plates [24]. Obviously, it can be noticed that the surface morphology of the sample sintered for $140 \mathrm{~h}$ reveals that it is more homogenous and have more pronounced alignment of its crystallites with c-axis. In addition, the plate-like grains were aligned to make denser and conductive sample. Such result was mentioned by Govea-Alcaide et al. [25]. Also, from Figure 4(e) a presence of bright areas with a small amounts of grains can be observed due to a possible melting of the synthesized material during the sintering process. It can be seen that the increase of sintering time to more than $140 \mathrm{~h}$ leads to the formation of a liquid phase that acts as insulating layers around the superconductor grains, which increases the resistance of grain boundaries and leads to a decrease in the transition temperature $\mathrm{T}_{\mathrm{c}}$ as indicated by Guilmeau et al. [26].

\section{Conclusion}

The effect of sintering time on the phase formation and superconducting properties were investigated. Results revealed that prolonged sintering time up to a certain maximum time could improve the critical temperature of stoichiometry composition and increase the high- $\mathrm{T}_{\mathrm{c}}$ (2223) phase. A remarkable increase in the critical temperature from 84 to $110 \mathrm{~K}$ was obtained with increasing sintering temperature from 120 to $140 \mathrm{~h}$. Our results also show that samples sintered for $140 \mathrm{~h}$ had the highest critical temperature $T_{c}=110 \mathrm{~K}$ and highest volume fraction of $\mathrm{Bi}(\mathrm{Pb})-(2223)$ high- $\mathrm{T}_{\mathrm{c}}$ phase $82.6 \%$. On the other hand, increasing sintering temperature to $160 \mathrm{~h}$ decreases the critical temperature and the volume fraction of the high $\mathrm{T}_{c}$ phase.

\section{References}

[1] Yi, H.P., Han, Z., Zhang, J.S., Liu, T., Li, M.Y., Fang, J., Liu, Q. and Zheng, Y.K. (2004) Research Status of the Manufacturing Technology and Application Properties of Bi-2223/Ag Tapes at Innost. Physica C, 412-414, 1073-1078. http://dx.doi.org/10.1016/j.physc.2004.01.114

[2] Arndt, T.J., Aubele, A., Fisher, B., Krauth, H., Sailer, B. and Szulczyk, A. (2002) Bi-2223 Tapes for Applications at High Temperatures and/or High Fields Designs, Long Length Processing and Properties. Physica C, 372-376, 887-890. http://dx.doi.org/10.1016/S0921-4534(02)00928-0

[3] Gul, I.H., Amin, F., Abbasi, A.Z., Anis-ur-Rehman, M. and Maqsood, A. (2006) Effect of $\mathrm{Ag}_{2} \mathrm{CO}_{3}$ Addition on the Morphology and Physical Properties of Bi-Based (2223) High-T $\mathrm{C}_{\mathrm{C}}$ Superconductors. Physica C, 449, 139-147. http://dx.doi.org/10.1016/j.physc.2006.08.004

[4] Truccato, M., Cagliero, S., Agostino, A., Panetta, M. and Rinaudo, G. (2006) Electrical Study of an Unusual Phase Transformation in a $\mathrm{Bi}_{2} \mathrm{Sr}_{2} \mathrm{Ca}_{2} \mathrm{Cu}_{3} \mathrm{O}_{10+\mathrm{x}}$ Whisker at Room Temperature. Superconductor Science and Technology, 19, 1003-1009. http://dx.doi.org/10.1088/0953-2048/19/10/003

[5] Takano, M., Takana, T., Oda, K., Kitaguchi, H., Miura, Y., Ikeda, Y., Tomii, Y. and Mazaki, H. (1988) High-Tc Phase Promoted and Stabilized in the Bi, Pb-Sr-Ca-Cu-O System. Japanese Journal of Applied Physics, 27, L1041-L1043. http://dx.doi.org/10.1143/JJAP.27.L1041

[6] Ekin, J.W., Salama, K. and Selvamanickam, V. (1991) High Transport Current Density up to $30 \mathrm{~T}_{\text {in }} \mathrm{Bulk} \mathrm{YBa}_{2} \mathrm{Cu}_{3} \mathrm{O}_{\mathrm{x}}$ and the Critical Angle Effect. Applied Physics Letters, 59, 360-364. http://dx.doi.org/10.1063/1.105595

[7] Guilmeau, E., Andrzejewski, B. and Noudem, J.G. (2003) The Effect of MgO Addition on the Formation and the Superconducting Properties of the Bi2223 Phase. Physica C, 387, 382-390. http://dx.doi.org/10.1016/S0921-4534(02)02360-2

[8] Gul, I.H., Rehman, M.A., Ali, M. and Maqsood, A. (2005) Effect of Vanadium and Barium on the Bi-Based (2223) Superconductors. Physica C, 432, 71-80. http://dx.doi.org/10.1016/j.physc.2005.07.013

[9] Aksan, M.A. and Yakyncy, M.E. (2004) Synthesis and Characterization of Er-Substituted Bi-2223 High-Tc Glass-Ceramic Superconductors. Journal of Alloys and Compounds, 385, 33-43. http://dx.doi.org/10.1016/j.jallcom.2004.04.135

[10] Coskun, A., Ekicibil, A., Ozcelik, B. and Kyymaç, K. (2005) Effects of Annealing Time on the Magnetic Properties of a $\mathrm{Bi}_{1.7} \mathrm{~Pb}_{0.29} \mathrm{Gd}_{0.01} \mathrm{Sr}_{2} \mathrm{Ca}_{3} \mathrm{Cu}_{4} \mathrm{O}_{12+\mathrm{y}}$ Superconductor Prepared by the Melt-Quenching Method. Chinese Journal of Physics, 43, 372.

[11] Siddiqi, S.A., Akhtar, B. and Ghauri, I.M. (2003) The Effect of 5\% Sb Doping on High Tc Superconductivity in $(\mathrm{Bi}, \mathrm{Pb})_{2} \mathrm{Sr}_{2} \mathrm{Ca}_{2} \mathrm{Cu}_{3} \mathrm{O}_{\mathrm{y}}$ Compound. Modern Physics Letters B, 17, 199-208. http://dx.doi.org/10.1142/S0217984903005081

[12] Iqbal, M.J. and Mehmood, R. (2006) Synthesis and Characterization of Antimony-Doped Bi-Based Superconducting 
Materials. Materials Science and Engineering: B, 135, 166-171. http://dx.doi.org/10.1016/j.mseb.2006.08.060

[13] Iqbal, M.J. and Mehmood, R. (2009) Improvement in High-Tc Phase Formationin (Thallium-Antimony) Doped Bismuth-Based Superconducting Materials. Journal of Alloys and Compounds, 477, 386-390. http://dx.doi.org/10.1016/j.jallcom.2008.10.006

[14] Fruth, V., Popa, M., Ianculescu, A., Stir, M., Preda, S. and Aldica, G. (2004) High-Tc Phase Obtained in the Pb/Sb Doped Bi-Sr-Ca-Cu-O System. Journal of the European Ceramic Society, 24, 1827-1830. http://dx.doi.org/10.1016/S0955-2219(03)00449-7

[15] Popov, A.G., Olevsky, F.M., Melnikov, V.S. and Pan, V.M. (1992) The Superconductivity of the Sb-Doped Bi-Pb-SrCa-Cu-O Compound. Superconductor Science and Technology, 5, 654-657. http://dx.doi.org/10.1088/0953-2048/5/11/010

[16] Liu, R.Y., Naito, H., Okuda, M., Nakahigashi, K., Takigawa, Y., Matsushita, T. and Kurosawa, K. (1992) Effects of Sb and $\mathrm{Pb}$ Doping on the High- $\mathrm{T}_{\mathrm{c}}$ Phase-Formation in Bi-Sr-Ca-Cu-O Superconductors. Superconductor Science and Technology, 5, 482-488. http://dx.doi.org/10.1088/0953-2048/5/8/005

[17] Tanaka, Y., Fukutomi, M., Asano, T. and Maeda, H. (1988) Effects of Synthesis Conditions on the Properties of a Superconducting Bi-Sr-Ca-Cu-O System. Japanese Journal of Applied Physics, 27, L548. http://dx.doi.org/10.1143/JJAP.27.L548

[18] Saleh, S.A. (2006) Studies on Sintering Effect on the Structural and Transport Properties of (2223) Phase. Physica C, 444, 40-44. http://dx.doi.org/10.1016/j.physc.2006.05.101

[19] Kocabas, K. (1998) Effect of Sintering Time On Sb Added BiPbSrCaCuO Superconducting Ceramics. Turkish Journal of Physics, 22, 437-440.

[20] Zargar Shoushtari, M. and Mousavi Ghahfarokhi, S.E. (2011) A Study of the Magnetic Properties of $\mathrm{Bi}_{1.64-x} \mathrm{~Pb}_{0.36} \mathrm{Cd}_{x} \mathrm{Sr}_{2} \mathrm{Ca}_{2} \mathrm{Cu}_{3} \mathrm{O}_{y}$ Superconductor. Journal of Superconductivity and Novel Magnetism, 24, 1505-1511. http://dx.doi.org/10.1007/s10948-010-0899-1

[21] Mizauno, Y., Sawa, A., Obara, H., Umeda, M. and Yamasaki, H. (1997) Field Sweep Rate Dependence of Magnetization and E-J Characteristics in $\mathrm{YBa}_{2} \mathrm{Cu}_{3} \mathrm{O}_{7}$ Films. Physica C, 282, 2255-2256.

[22] Zargar Shoushtari, M., Mousavi Ghahfarokhi, S.E. and Farbod, M. (2008) The Effect of Cd Doping on Bi-Based Superconductor. Journal of Applied Sciences, 8, 2613-2618. http://dx.doi.org/10.3923/jas.2008.2613.2618

[23] Muné, P., Govea-Alcaide, E. and Jardim, R.F. (2003) Influence of the Compacting Pressure on the Dependence of the Critical Current with Magnetic Field in Polycrystalline (Bi-Pb) ${ }_{2} \mathrm{Sr}_{2} \mathrm{Ca}_{2} \mathrm{Cu}_{3} \mathrm{O}_{\mathrm{x}}$ Superconductors. Physica C, 384, 491500. http://dx.doi.org/10.1016/S0921-4534(02)02060-9

[24] Ben Azzouz, F., M’chirgui, A., Yangui, B., Boulesteixand, C. and Ben Salem, M. (2001) Synthesis, Microstructural Evolutionand the Role of Substantial Addition of $\mathrm{PbO}$ during the Final Processing of $(\mathrm{Bi}, \mathrm{Pb})-2223$ Superconductors. Physica C, 356, 83-96. http://dx.doi.org/10.1016/S0921-4534(01)00124-1

[25] Govea-Alcaide, E., Jardim, R.F. and Muné, P. (2005) Correlation between Normal and Superconducting Transport Properties of $\mathrm{Bi}_{1.65} \mathrm{~Pb}_{0.35} \mathrm{Sr}_{2} \mathrm{Ca}_{2} \mathrm{Cu}_{3} \mathrm{O}_{10+\delta}$ Ceramic Samples. Physica C, 423, 152. http://dx.doi.org/10.1016/j.physc.2005.04.009

[26] Guilmeau, E., Andrzejewski, B. and Desgardin, G. (2002) The Effect of Bi-2201 Phase on the Intergranular Critical Field and Current Density in Bi2223 Superconductors. Physica C, 377, 304-312. http://dx.doi.org/10.1016/S0921-4534(01)01207-2 